MUZIKOLOŠKI ZBORNIK - MUSICOLOGICAL ANNUAL VI, LJUBLJANA 1970

\title{
ZLOGOVANJE V LJUDSKI PESMI
}

\author{
Zmaga Ku m e r (Ljubljana)
}

Časi, ko so raziskovalci naše ljudske pesmi iskali $\mathrm{v}$ njej le značilnosti, ki bi jih bilo mogoče označiti kot zgolj slovenske, še niso zelo daleč. Vendar se je naše gledanje na ljudsko pesem odtlej bistveno spremenilo. Tako kot posebnosti nas zdaj zanima njena vsakdanja podoba, pa tudi vse tisto, kar ima slovenska ljudska pesem skupnega s pesmijo drugih narodov. Nepristransko skušamo ugotavljati zakonitosti, po katerih se oblikuje, smernice njenega razvoja in vse drugo, kar je vplivalo nanjo. Treba je biti radoveden, imeti odprte oči in ušesa, da opazimo tudi navidez nepomembne pojave. Nikoli ne vemo, če se morda kdaj ne izkažejo kot nekaj bistveno značilnega. Zbiranje gradiva ne sme biti nikoli zgolj tehnično delo, čeprav ga danes opravljamo $\mathrm{s}$ tehničnimi pomagali in ne zapisujemo neposredno po petju. Zbiralec se mora zavedati, da ima opravka ne samo z živimi ljudmi, marveč da je tudi gradivo v nekem smislu živo, v nenehnem spreminjanju. S spretno zastavljenimi vprašanji, ki jih narekujejo $\mathrm{z}$ leti nabrane izkušnje, je treba izvabiti iz pevca poleg pesmi še čim več podatkov, da si moremo ustvariti podobo o tem, kaj, kdaj in kako v nekem kraju ali okolišu pojejo. Ko potem z magnetofonskega traku prepisujemo melodijo in besedilo, moramo opravljati to čim natančneje, ker le tako se nam pokaže, kaj je osebna značilnost nekega pevca, kaj je značilnost kraja ali pokrajine, kaj pa morda velja za petje naše pesmi nasploh. Sprva se je pač treba zadovoljiti z ugotovitvami, ker ni mogoče takoj videti zveze med pojavi, razen tega je treba za popolno razumevanje, ki vodi do odkritja zakonitosti, upoštevati še tuje gradivo. Potrebna je primerjava s pesmijo drugih narodov, ugotavljanje podobnih pojavov drugod in iskanje morebitnih zvez - brez predsodkov in napačne sramežljivosti ali nepotrebnega ponosa -, da se pokažejo značilnosti naše pesmi in petja $\mathrm{v}$ pravi luči. Včasih pa se primeri, da tuji raziskovalec opozori pri pesmih njegove dežele na pojav, ki smo ga tudi sami opazili $\mathrm{v}$ domačem gradivu. Veseli spoznamo, da torej stvar, ki smo jo imeli sprva le za drobno zanimivost, nikakor ni docela nepomembna, in da bi jo kazalo o priliki vzeti $\mathrm{v}$ pretres.

Tako me recimo že dalj časa zanima vprašanje zlogovanja $v$ naši ljudski pesmi. Ker se mi zdi prav, da zapisujem besedilo pod notni zapis natanko po petju (ne glede na slovniška pravila in predpise, ki veljajo za zborovsko ali solistično petje skladb umetne glasbe), sem nehote postala pozorna nanj. $\mathrm{Na}$ 
vprašanje zlogovanja pesemskih besedil je naletel - neodvisno od nas tudi češki muzikolog Dušan Holý. V svoji knjigi »Probleme der Entwicklung und des Stils der Volksmusik« (Brno 1969) pravi na str. 176, da besedilo vpliva na ritem pevskega izražanja. Pevec da se nikoli ne trudi deliti takta matematično tj. na tri časovno enake vrednosti, marveč poje vedno $\mathrm{v}$ plesnem ritmu, kakor ga pač doživlja. »Tudi ne raztrga pesmi na zloge, kot ponavadi shematično delamo pri zapisovanju«, pravi Holý. »Pogosto se zlogi zlivajo drug $\mathrm{v}$ drugega. Ugotavljamo namreč, da zbiralec ponavadi deli besedo ,zapuatim', - ki se poje v $2 / 4$ taktu - po znanih slovničnih pravilih ,za-puatim', medtem ko poje pevec ,zap-ua-tim'. S strani tona je to velika razlika. Pevci oddelijo soglasnik -p- od 2. zloga $\mathrm{v}$ taktu in ga pripojijo 1. zlogu. Pojejo torej v skladu s plesnim ritmom. « Holý obravnava v svoji knjigi le češke plesne pesmi iz pokrajine Hornácko, ne pa tudi drugih, zato se sklicuje na plesni ritem. Kolikor mi je znano, doslej še nihče ni opozoril na te probleme, niti med lingvisti, niti med folkloristi. Čeprav zapisi ljudskih pesmi ne morejo biti vsestransko uporabljivo gradivo za jezikoslovne raziskave, se mi vendar zdi, da utegnejo naša opazovanja o zlogovanju v pesmi zanimati tudi sloveniste. Pojav sicer še ni dovolj raziskan, vendar ne bo prezgodaj vsaj opozoriti nanj.

$\mathrm{Na}$ Slovenskem plešemo povečini ob instrumentalni spremljavi - plesi s petjem so pri nas redki in plesne pesmi navadno le parafraze, ne pa sestavni del plesa. Besedilo naših pesmi se torej ne podreja plesnemu ritmu, kot je to pri obravnavanih čeških primerih ugotovil Holý, pač pa melodiji oziroma metroritmičnemu obrazcu. Celo pri pripovednih pesmih, kjer je pozornost pevcev in poslušalcev usmerjena $\mathrm{v}$ besedilo - verzificirano zgodbo - ima ritem melodije tolikšno veljavo, da mu pevci brez oklevanja žrtvujejo naravni besedni naglas. Koliko laže store to pri drugih pesmih, kjer je $\mathrm{v}$ ospredju melodija, lepo petje. Nekaj zgledov iz raznih pokrajin to jasno kaže:

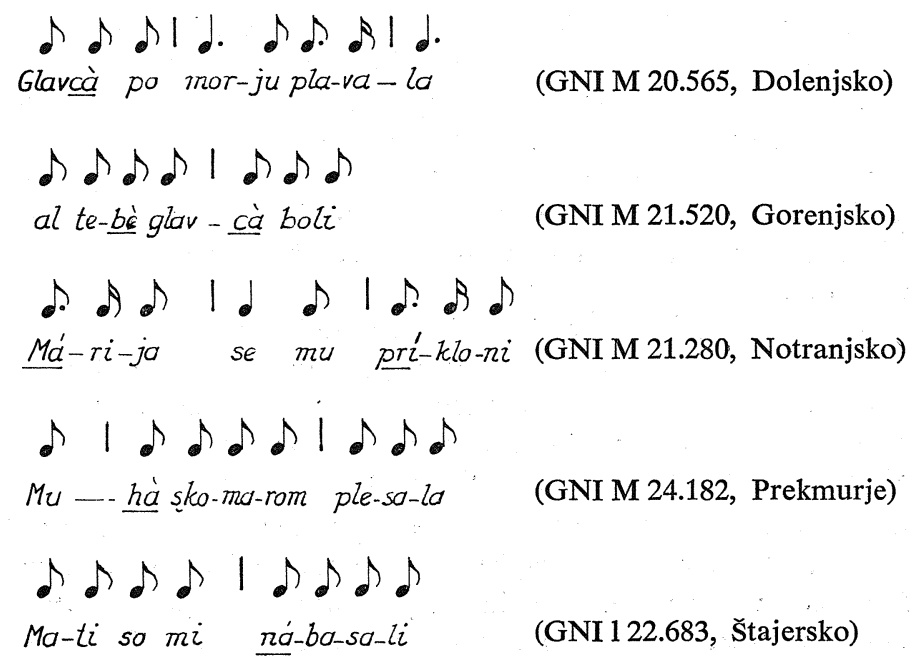


V starejših slovenskih pesmih se besedilo tako ureja v verze, da metroritmični obrazec ne dela jeziku sile. Npr.:

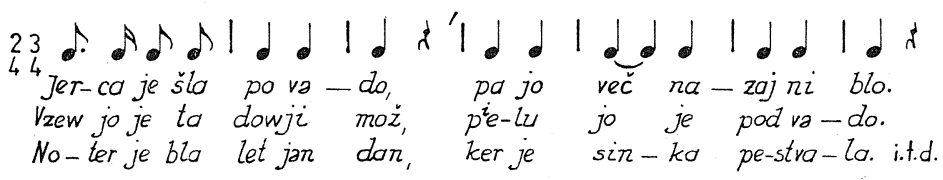

(GNI M 20.713)

Število zlogov je $\mathrm{v}$ takih pesmih ves čas enako, le včasih je treba zaradi kakšnega zloga, ki je preveč ali premalo, ritem melodije prilagoditi. Sicer pa se metroritmični obrazec melodije in besedila lepo ujemata. Npr.:

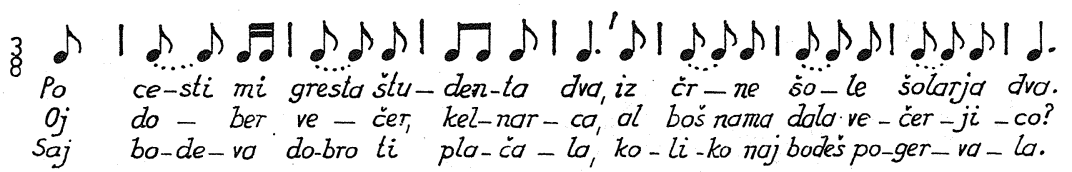

(GNI M 22.684)

Prav ta urejenost je tudi eden izmed vidikov za presojanje starosti variant neke pesmi. Kadar opazimo, da se melodija in besedilo $s$ težavo ujemata, je to navadno znamenje, da se je $\mathrm{v}$ pesmi že začel razkroj in da spada besedilo med mlajše variante.

Naši prvi zapisovalci pesmi se za melodije niso zmenili. $V$ pesmih so gledali besedno umetnino, pomembno jim je bilo besedilo, njegova vsebina, ne pa tudi oblika. Zato so si dovoljevali jezikovne popravke, nadomeščali germanizme s slovenskimi izrazi, dajali besedam slovnično pravilno obliko in se niso vprašali, kako bi bilo mogoče takó zapisano besedilo peti. Različno dolgi verzi $\mathrm{v}$ naših starejših pesemskih zapisih so zavedli I. Grafenauerja $\mathrm{v}$ teorijo o pripovedni dolgi vrstici ${ }^{1}$ in $\mathrm{F}$. Marolta $\mathrm{v}$ domnevo o nekakšnem koralnem načinu petja najstarejših pesmi, ${ }^{2}$ kar se je oboje pozneje izkazalo kot zmotno. $^{3}$ Te ugotovitve o napačnem ravnanju prvih zapisovalcev pa seveda ni vzeti kot obsodbo, saj vemo, da so ravnali v skladu s tedanjimi nazori. Kdo ve, kakšne napake delamo mi, ne da bi se jih prav zavedali! Sicer pa si je celo F. Kramar, eden naših najboljših zapisovalcev pesmi z melodijami, dal ponavadi zapeti le prvo kitico pesmi, drugo besedilo pa narekovati. Znano je, da so pevci nezanesljivi pripovedovalci verzov in da izpeljejo besedilo pesmi do konca brez napake le v primeru, da ga pojo. Ko je Kramar svoje zapise prepisoval na čisto, da bi jih poslal »Odboru za nabiranje slov. narodnih pesmi $\mathrm{z}$ napevi«, za katerega je zbiral, je opazil, da narekovanih verzov ni

1 I. Grafenauer, Lepa Vida. Študija o izvoru, razvoju in razkroju narodne balade o Lepi Vidi, Ljubljana 1943, 130-172.

2 o.c., 131.

3 Prim. V. Vodušek, Arhaični slovanski peterec-deseterec v slovenski ljudski pesmi, Slovenski etnograf XII/1959. 


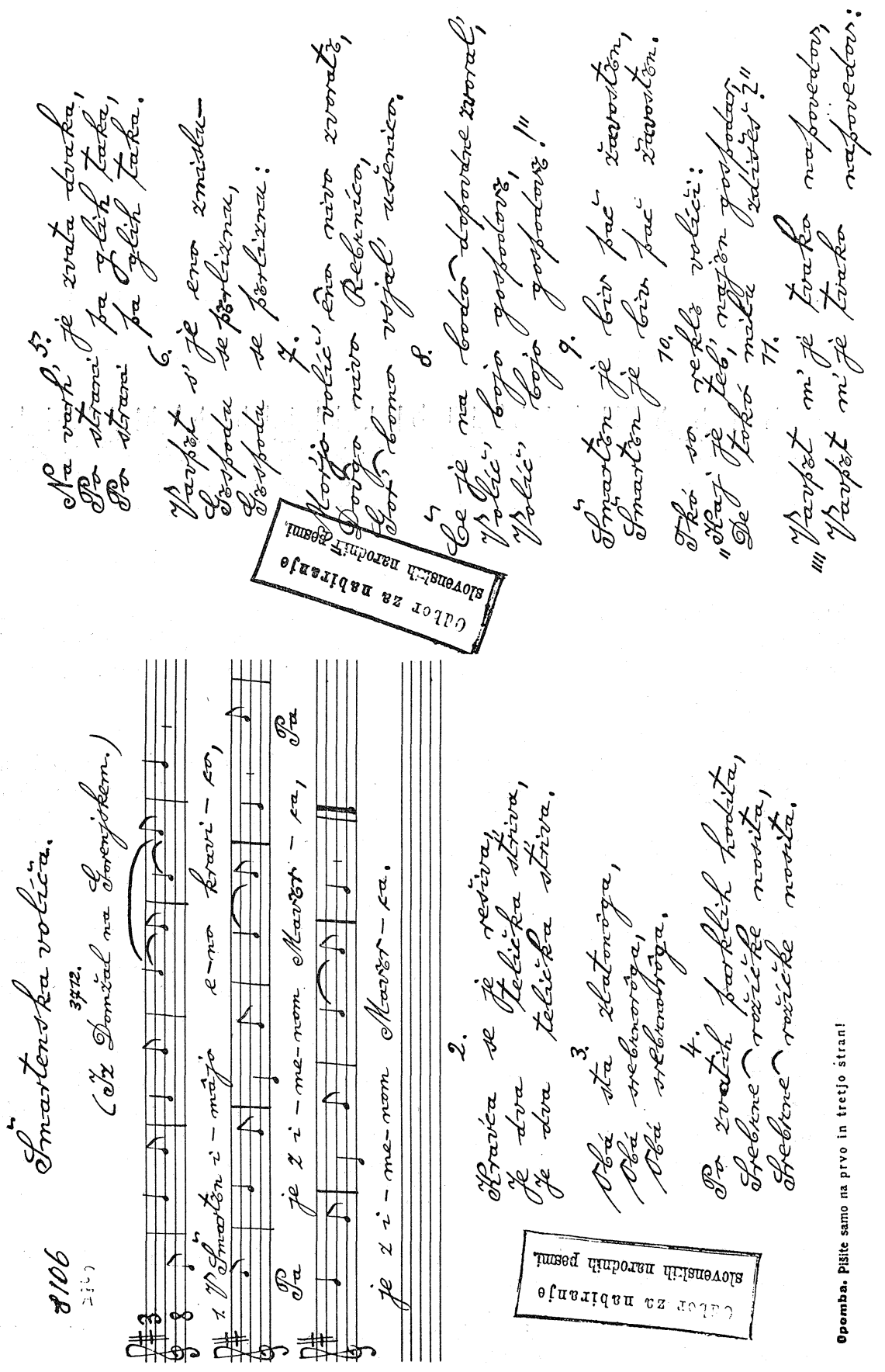


mogoče vselej peti po melodiji prve kitice. Zato je $\mathrm{z}$ vezaji nakazal, kje bi bilo treba zloge strniti, da bi se besedilo prav »izšlo«, kar kaže primer $\mathrm{v}$ faksimilu.

Ko v Glasbeno narodopisnem inštitutu prepisujemo pesmi z magnetofonskega traku, pišemo melodijo za vsako kitico posebej, eno pod drugo, da je mogoče natančneje in sproti zaznamovati morebitne spremembe. Kajpak je treba pod zapis melodije pisati tudi besedilo natanko po petju in tako se sama po sebi ponuja priložnost za opazovanje zlogovanja.

O deljenju besed je bilo pri nas že marsikaj napisanega, ${ }^{4}$ ne pa tudi o zlogovanju, če izvzamemo navodila pevskih pedagogov. Ti trdijo, ${ }^{5}$ da so za petje najbolj primerni odprti zlogi, tj. taki, ki se končujejo s samoglasnikom. Zato da je treba soglasnike jemati k naslednjemu zlogu. Izjema so zvočniki, ki lahko s spredaj stoječim samoglasnikom tvorijo diftong. Tudi skupin -ml in -mr ne smemo deliti. Potemtakem je treba po pevsko zlogovati npr. takole: le-pši (ne: lep-ši, kot bi bilo po pravopisu), pi-hni-ti (ne: pih-ni-ti), ra-zve-za-ti (ne: raz-ve-za-ti), raj-ski, pre-mlad, ra-zga-nja-ti (ne: raz-ga-nja-ti), bre-zda-nji (ne: brez-da-nji) itd.

Šolani pevci se morajo ravnati seveda po teh pravilih, saj jim je tudi pevska izreka natanko določena in $\mathrm{v}$ marsičem drugačna od zborne izreke. Ljudskim pevcem je vse to neznano, zlasti tistim, ki niso nikoli peli v kakšnem cerkvenem ali drugačnem zboru. Pojo po občutku in so pozorni včasih bolj na melodijo, drugič na besedilo, nikoli pa ne mislijo na izgovorjavo, na oblikovanje glasov, tona ipd. O tem se lahko prepričamo, če poskušamo čim natančneje opazovati, kaj oziroma koliko zapoje pevec kot en zlog. Pri tem se ne smemo zadovoljiti le s primeri iz enega kraja ali pokrajine, marveč pregledati gradivo iz različnih narečnih območij. Seveda je vsak zapis bolj ali manj subjektivna stvar. Nikoli se ni mogoče popolnoma zanesti, da si slišal natanko tako, kot je pevec zapel. Samo aparat lahko povsem objektivno zaznamuje pojave. Za prepis ali razlago pa je že spet potreben človek in je torej neka mera subjektivnosti - čeprav še tako majhna - neizbežna. To velja $\mathrm{v}$ enaki meri za zapise melodij kot za zapise besedila in $\mathrm{v}$ našem primeru za zaznamovanje zlogovanja.

Ko pregledujemo zapise besedil po magnetofonskih posnetkih, najprej opazimo, da ljudski pevci $\mathrm{v}$ mnogih primerih zlogujejo drugače, kot bi bilo prav po pevskih načelih. Zgodi se, da isti pevec $\mathrm{v}$ isti pesmi zloguje besedo enkrat tako, drugič drugače. Npr.:

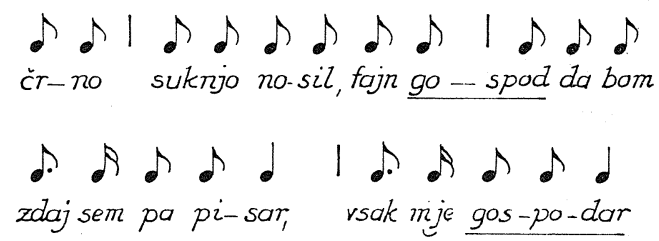

(GNI M 27.788)

4 Prim. razen Slovenskega pravopisa, Ljubljana 1962 še: T. Bajec, O deljenju besed, Jezik in slovstvo V/1959-1960; J. Toporišič, Deljenje besed v slovenščini, o. c.; B. Urbančič, K predlogu o deljenju besed, o. c.

5 Prim. A. Gröbming, Zborovodja, II. del, Ljubljana 1948, 170. 


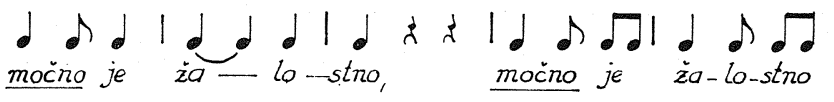

(GNI M 24.202)

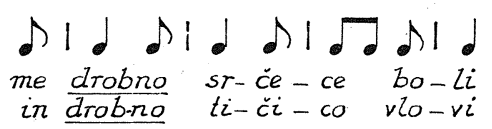

(GNI M 27.764)

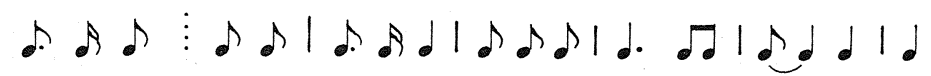

da_i-ma że druz-ga fan-ti-ča, dai-ma że drui-zga fan-ti-ča (GNI M 23.899)

d D. 1 d d 1 o

sli-saw sem pti-čke pet

$d A \mid \lambda \phi$

sli-šaw sem ptič-ke pet

(GNI M 26.868)

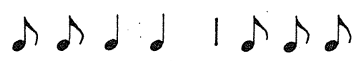

ce nam misles - te kej dat

ce nam misla_ste kej dat

(GNI M 24.303)

Po pevsko je treba soglasnike jemati $\mathrm{k}$ naslednjemu zlogu, ljudski pevci pa večkrat končajo zlog s soglasnikom. Npr.:

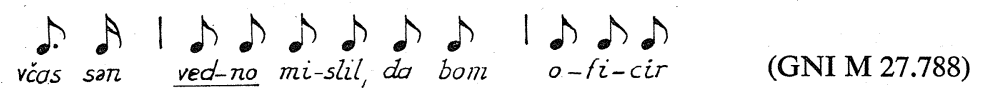

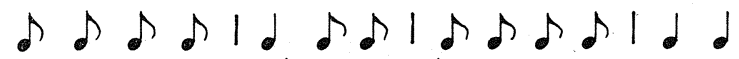

$$
\begin{aligned}
& \text { ed-no rav-no drei-vo, na tri vr-he koś-na-to } \text { (GNIM 24.178) }
\end{aligned}
$$

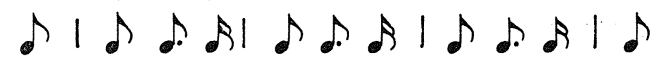$$
\text { bod mo-ja, bod mo-ja, tbom leś-ni-kov daw }
$$

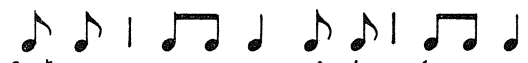

frišna ro-sa, oj-stra ko-sa

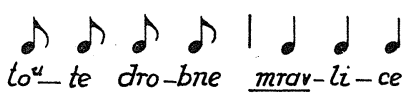

$\lambda \rho 1 \rho d \rho \lambda$

vmes pa na-gelj, roż-ma-rin

(GNI M 23.312) 
Včasih delijo dvojice oziroma skupine soglasnikov, ki jih ponavadi pišemo skupaj. Npr. st-, ks-, sp-, šč-, ipd. Npr.:

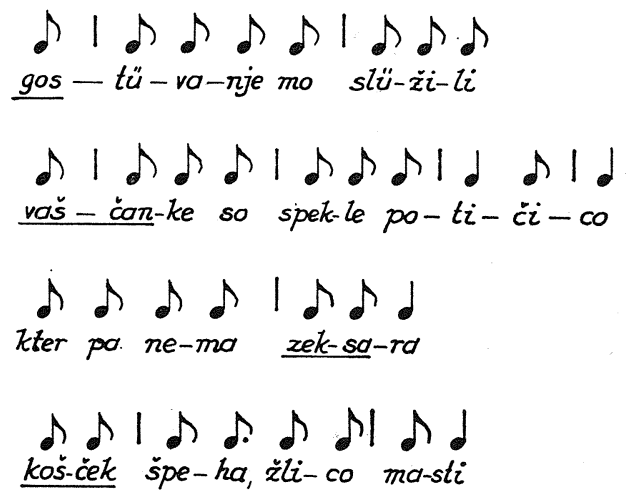

(GNI M 24.325)

Ker ne velja pravilo odprtih zlogov, se katerikrat začudimo, kako da je pevec njemu na ljubo (ali res?) ohranil nerodno izgovorljivi zlog, namesto da bi delil kot drugod. Npr.:

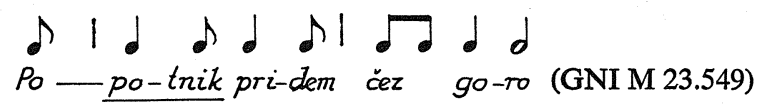

Zlasti $\mathrm{v}$ osrednjih slovenskih narečjih, ki so izvedla t.i. moderno vokalno redukcijo, lahko nastane zlog tudi z opustitvijo samoglasnika $\mathrm{v}$ besedi, ponavadi v zaimku in pomožnem glagolu. Tako skrčene besede - dve ali tri - tvorijo en sam, redkeje dva zloga, posebno če naj se ritem verza ujema $\mathrm{z}$ ritmom melodije.

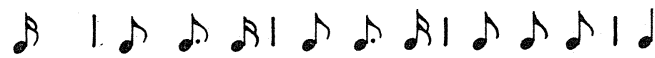

bod mo-ja, bod mo-ja, tbom le-šen-kov daw (GNI M 23.885)

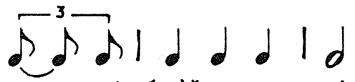

čém glih kajžca zgo-ri

(GNI M 23.196)

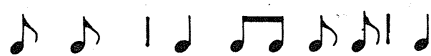

das tak moč-no ża-lost-na

(GNI M 21.347)

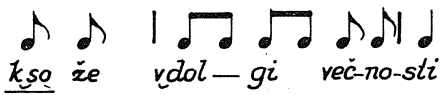

(GNI M 22.386)

d 1 d. dd $1 d . d d$

'ko-koj bo fle-tno vtroj-mukos

(GNI M 22.410) 
Nekateri predlogi se zaobešajo na predhodno ali naslednjo besedo, kakor se pevcu zdi pripravneje zlogovati. Npr.:

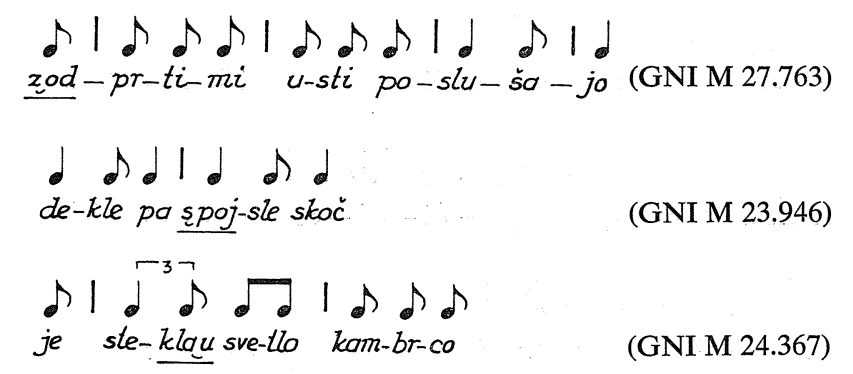

Včasih združijo pevci $\mathrm{v}$ en zlog konec in začetek dveh sosednjih besed, če je mogoče tam izgovoriti diftong, se pravi, če ga izgovarjajo tudi v vsakdanjem narečnem govoru. Spet se to primeri večkrat $\mathrm{v}$ osrednjih narečjih kot $\mathrm{v}$ obrobnih. Npr.:

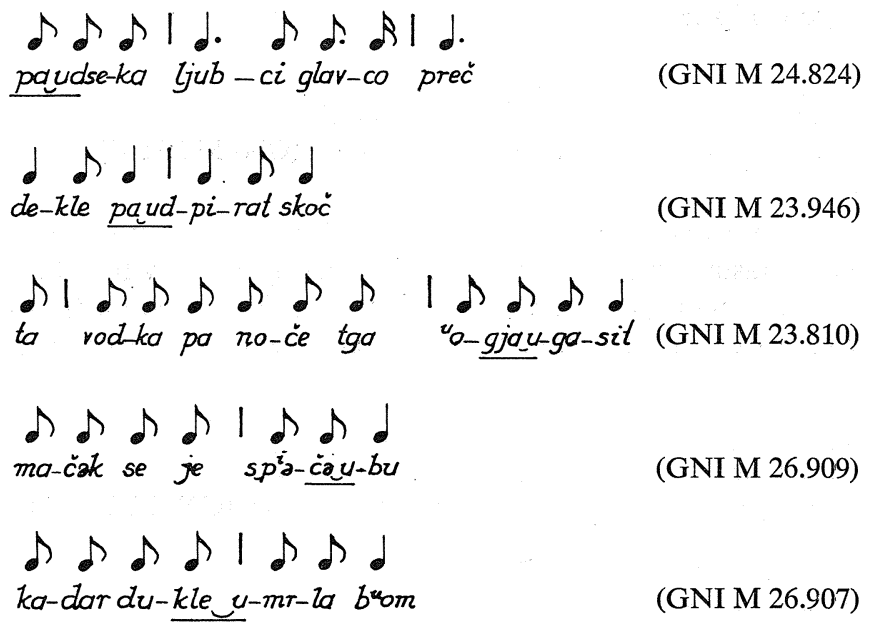

S temi zgledi kajpak nikakor ni povedano vse, kar se dá dognati o zlogovanju. Problem je komaj načet. Posebej bi bilo treba raziskati, ali morda ne vpliva na zlogovanje zgradba melodije, zlasti ritem, recimo punktirani, metrični poudarki, podaljšave tonov ipd. Ali pa je narobe in vpliva besedni izgovor na oblikovanje melodičnega ritma?

Morda bo kdo dejal, da zganjamo nepotrebno dlakocepstvo, ko posebej zaznamujemo vse podrobnosti zlogovanja, celo slučajno nastale zloge. Vezaji se bodo zdeli še celo odveč, češ da že vsak ve, kako vežemo predloge $\mathrm{k}$ besedam ali kako se zlivajo $\mathrm{v}$ enega zlogi sosednjih besed. $\mathrm{V}$ resnici bi bili brez vezajev dostikrat $\mathrm{v}$ zadregi, ker bi mislili, da zapisovalec $\mathrm{v}$ primeru, kot je npr. 


$$
\begin{aligned}
& \lambda a-d a r \\
& d u-k l e-u-m r-l a \\
& d
\end{aligned}
$$

ni zaznamoval ritmične prilagoditve melodije. Pevka bi namreč lahko takole zapela:

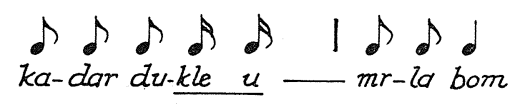

Verz pa se dá zlogovati tudi drugače in ne bi bilo prvič, da bi kdo zapel:

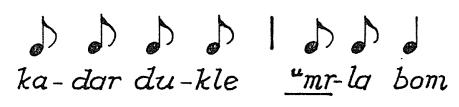

Poudarek je $\mathrm{v}$ tem primeru na $-\mathrm{r}$, -u pa je oslabljen. Ker dopušča netočen zapis različne razlage, se mi zdi nujno, da natanko zapišemo izgovarjavo ter označimo tudi zlogovanje s pomišljaji in vezaji. Brez tega pri zapisovanju pesemskih besedil ne gre, če naj bralec iz zapisa razbere tudi ritem verzov ter njihovo razmerje do ritma melodije.

Pri zapisih besedila brez melodije kajpak opustimo pomišljaj in pišemo besede strnjeno, vezaju pa se tudi tu ne dá vselej izogniti, ker bi sicer dostikrat ne vedeli, če je na meji med dvema besedama hiat ali je izgovor diftongičen. $\mathrm{Da}$ to ni vseeno, dokazujejo otroške izštevalnice, ki so redno brez melodije, zato pa ostro ritmizirane. To zahteva že njihova povezanost $\mathrm{z}$ gibanjem: pri izgovarjanju besedila kaže otrok, ki izšteva, na tovariše okrog sebe. Za zgled naj navedemo vsaj eno:

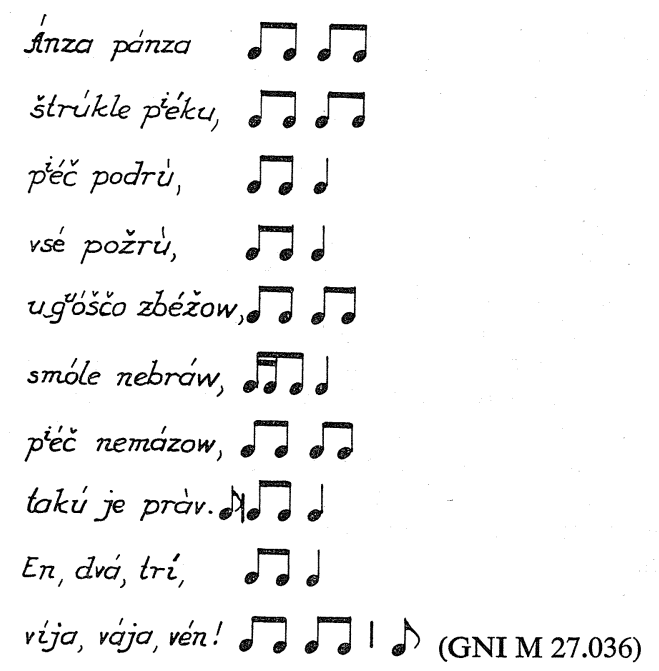


Raziskovanje ritma naših vprašalnic je za zdaj še nenačet problem, kar pa ne pomeni, da zapise gradiva zanj lahko zanemarjamo. Kolikor mi je znano, se tudi proznega govora doslej še nihče ni lotil z vidika ritma, čeprav mora zlasti dialektologa zanimati, kako ljudje izgovarjajo besede $\mathrm{v}$ stavkih, kje in kako jih povezujejo, kakšne besedne tvorbe pri tem nastajajo in zakaj, kakšen je ritem vsakdanjega govora in kakšna njegova melodija. Čeprav se raziskovalcu pesemskih besedil zastavljajo drugačna vprašanja kot dialektologu, ki bi se lotil narečne proze, se bosta pri delu vendar večkrat srečala. Naj bi bil ta kratki sestavek opozorilo, da nas vse skupaj čaka še veliko zanimivega, preden nam bo uspelo odkriti zakonitosti, ki oblikujejo našo ljudsko pesem in vsakdanjo govorico. Kakor raziskovanje pesemskih besedil ni le naloga folkloristov, tako je tudi raziskovanje ljudske govorice več kot samo jezikoslovna zadeva, tu se srečata ljudska glasbena in besedna umetnost.

\section{SUMMARY}

A modern ethnomusicologist should regard nothing he observes when recording, transcribing or exploring the folk tradition as insignificant. For it may happen that something he considers as only of little interest proves to be an important, characteristic feature. One of such phenomena is for instance the scansion of the texts of folk songs. Until now nobody has written widely on this subject. It is mentioned only by D. Holý in his book »Probleme der Entwicklung und des Stils der Volkmusik « (Brno 1969, p. 176) where he says - when dealing with dance songs - that the singers do not scan according to the rules of grammer but sing according to the dance rhythm.

In Slovenia there are only a few genuine dance songs. However, the rhythm of melody is even in narrative songs of such importance that, if necessary, the singers sacrifice, the word stress to it. The first Slovene ethnologists considered the folk songs only as a literary art and took no notice of the melodies. Later recorders of the melodies paid attention primarily to the tune of the song. If the text was dictated to them they only seldom took heed of its harmony with the melody, let alone paying attention to the scansion.

Only when transcribing from tape, writing the melody and text of each stanza directly one under the other, can we observe how the folk singers divide the syllables. This phenomenon is interesting, but it is not yet sufficiently explored. Until now it was found that the folk singers do not always scan according to the principles of singing, nor according to the rules of grammer, and that one and the same word is not necessarily scanned the same way twice. They often end a syllable with a consonant, divide a consonant group, which we usually write together or combine neighbouring syllables in a diphtong or leave together syllables which are difficult to pronounce etc.

An exact marking of scansion is not an end to itself, but rather a good means to find out the rhythm of the verse and its relation to the rhythm of the melody. In this way our attention is also drawn to he rhythmic form of prose speech which is still a blank chapter of Slovene dialectology. This short article acts as a kind of warning that we still have a great number of problems to explore, before we succeed in finding out the principles which govern our folk song and our everyday speech. 